\title{
BMJ Open Implications of aligning full registration of doctors with medical school graduation: a qualitative study of stakeholder perspectives
}

\author{
$\mathrm{K}$ L Mattick, ${ }^{1} \mathrm{~K}$ Kaufhold, ${ }^{2} \mathrm{~N}$ Kelly, ${ }^{3} \mathrm{~J}$ A Cole, ${ }^{4} \mathrm{G}$ Scheffler, ${ }^{5} \mathrm{C}$ E Rees, ${ }^{6}$ A Bullock, ${ }^{7}$ \\ G J Gormley, ${ }^{8}$ L V Monrouxe ${ }^{9}$
}

To cite: Mattick KL,

Kaufhold K, Kelly N, et al. Implications of aligning full registration of doctors with medical school graduation: a qualitative study of stakeholder perspectives. BMJ Open 2016;6:e010246. doi:10.1136/bmjopen-2015010246

- Prepublication history for this paper is available online. To view these files please visit the journal online (http://dx.doi.org/10.1136/ bmjopen-2015-010246).

Received 12 October 2015 Revised 20 November 2015 Accepted 30 November 2015

CrossMark

For numbered affiliations see end of article.

Correspondence to Professor KL Mattick; k.l.mattick@ex.ac.uk

\section{ABSTRACT}

Objectives: The Shape of Training report recommended that full registration is aligned with medical school graduation. As part of a General Medical Council-funded study about the preparedness for practice of UK medical graduates, we explored UK stakeholders' views about this proposal using qualitative interviews ( 30 group and 87 individual interviews) and Framework Analysis.

Setting: Four UK study sites, one in each country. Participants: 185 individuals from eight stakeholder groups: (1) foundation year 1 (F1) doctors ( $n=34)$; (2) fully registered trainee doctors $(n=33)$; (3) clinical educators ( $n=32)$; (4) undergraduate/postgraduate Deans, and Foundation Programme Directors $(n=30)$; (5) other healthcare professionals $(n=13) ;(6)$ employers $(n=7)$; (7) policy and government $(n=11)$; (8) patient and public representatives $(n=25)$.

Results: We identified four main themes: (1) The F1 year as a safety net. patients were protected by close trainee supervision and 'sign off' to prevent errors; trainees were provided with a safe environment for learning on the job; (2) Implications for undergraduate medical education: if the proposal was accepted, a 'radical review' of undergraduate curricula would be needed; undergraduate education might need to be Ionger; (3) Implications for F1 work practice: steps to protect healthcare team integration and ensure that $F 1$ doctors stay within competency limits would be required; (4) Financial, structural and political implications: there would be cost implications for trainees; clarification of responsibilities between undergraduate and postgraduate medical education would be needed. Typically, each theme comprised arguments for and against the proposal.

Conclusions: A policy change to align the timing of full registration with graduation would require considerable planning and preliminary work. These findings will inform policymakers' decision-making. Regardless of the decision, medical students should take on greater responsibility for patient care as undergraduates, assessment methods in clinical practice and professionalism domains need development, and good practice in postgraduate supervision and support must be shared.

\section{Strengths and limitations of this study}

- This study follows the Shape of Training report, ${ }^{3}$ which recommended that full registration is aligned with the point of graduation from medical school.

- The current study provides unique and robust empirical data that contribute to a nuanced understanding of the implications of the report's recommendations and for the implementation process.

- The number and diversity of our participants is a key strength and our interview approach was well placed to explore the perspectives of a wide range of stakeholders.

- Alignment of full registration and medical school graduation was only one of a number of topics covered in the interviews; thus, the depth of discussion around this issue was reasonably limited.

\section{INTRODUCTION}

Medical education and training have changed substantially in recent years, in the UK and further afield. ${ }^{12}$ Within this state of flux, there have been consistent and recurrent themes. One is the incremental responsibility with appropriate supervision required by medical students and trainees. Another is the clear demarcation of training milestones, such as graduation, joining the medical register and formal sign-off at completion of training.

Currently in the UK, after graduating from medical school, junior doctors are provisionally registered with the General Medical Council (GMC) and work for a year under close supervision as foundation year 1 (F1) doctors, with some restrictions on their practice. After successful completion of the F1 year, they are fully registered and proceed through year 2 of the Foundation Programme followed by core and specialty 
training, before being awarded a Certificate of Completion of Training (CCT). The training process can take anywhere from 5 to 10 years after graduation, depending on the clinical specialty. As part of an independent review of medical education and training resulting in the Shape of Training report, ${ }^{3}$ a number of initiatives to improve training were recommended, including a 'broad-based' 2-year programme in general practice, core medicine, paediatrics and psychiatry prior to joining the second year of training in one of these specialties, and a replacement for the CCT called the Certificate of Specialty Training.

However, these changes may not address the significant concerns that exist about the training and support of junior doctors, with only $70 \%$ agreeing or strongly agreeing that they were well prepared for their first F1 post, ${ }^{4}$ alarming levels of career-related ill health among junior doctors, ${ }^{5}$ and concerns around retention of doctors. ${ }^{6}$ Furthermore, fragmentation of support for F1 doctors has been highlighted as problematic, particularly around fitness to practice where medical schools are responsible for $\mathrm{F} 1$ doctors who may be working remotely.

The Shape of Training report also recommended that full registration with the GMC 'should move to the point of graduation from medical school, subject to the necessary legislation being approved by Parliament and provided educational, legal and regulatory measures are in place' (p.32). ${ }^{3}$ Such a change would have clear and substantial implications for undergraduate and postgraduate training; thus, Greenaway highlighted that 'moving the point of full registration will have to be fully examined' (p.32). ${ }^{3}$

The data presented in this manuscript were collected as part of a larger programme of GMC-funded research that aimed to understand the extent to which current UK medical graduates are prepared for practice, via literature reviews, narrative interviews and longitudinal audio diaries. ${ }^{7}$ During the narrative interviews, we explored different stakeholder groups' views and perspectives on the proposed change to align full GMC registration at the point of graduation. In asking these questions, our aim was to provide robust empirical data on the nuanced perspectives on this important issue and make recommendations to maximise the success of the next steps if the proposal is implemented.

\section{METHODS}

\section{Research question}

What are stakeholders' views about the proposal to align the time of full registration of doctors to the point of graduation?

\section{Participants}

As part of a GMC-funded multisite, cross-sectional, qualitative narrative interview study about the preparedness for practice of UK medical graduates, ${ }^{7} 185$ individuals from 8 stakeholder groups were recruited from 4 study sites (table 1), one in each UK country. The stakeholder groups were: (1) F1 doctors (F1); (2) fully registered trainee doctors (FRTD); (3) clinical educators (CE), (4) undergraduate/postgraduate Deans, and Foundation Programme Directors (D_FP); (5) other healthcare professionals (HCP); (6) employers (EMP); (7) policy and government (GVT); and (8) patient and public representatives (PPR). The participants were diverse in terms of age, gender and ethnicity (table 2).

\section{Recruitment}

University and/or medical school ethics committee approval and/or hospital trust approvals from all four study sites were received in July and August 2013, prior to recruitment. Multiple methods of recruitment were employed to maximise participation, including verbal announcements, email, noticeboards and snowballing through various organisations and networks (eg, patient groups). It is not possible to state how many potential participants were approached and/or received a study invite (and thereby calculate a participation rate), due to our multiple methods of recruitment, but no potential participants dropped out or actively declined. Information sheets were sent to prospective participants and consent forms signed prior to interview.

\section{Data collection and analysis}

Data were gathered through individual or group interviews between November 2013 and March 2014. We held 30 group and 87 individual interviews (185 participants in total), resulting in 94:30:46 (h:min:s) of audio recordings (with an average of 0:42:26 per individual interview and 1:05:59 for group interviews). All co-authors undertaking interviews (JC, KK, NK, GS and LM) followed the same protocol and attended a 2-day training session to

\begin{tabular}{|c|c|c|c|}
\hline \multirow[b]{2}{*}{ Stakeholder group } & \multicolumn{2}{|c|}{ Interviews ( $n=185)$} & \multirow[b]{2}{*}{ Total } \\
\hline & Group* & Individual & \\
\hline F1 Doctors (F1) & $7(n=18)$ & 16 & 34 \\
\hline $\begin{array}{l}\text { Fully Registered Trainee } \\
\text { Doctors (FRTD) }\end{array}$ & $6(n=25)$ & 8 & 33 \\
\hline Clinical Educators (CE) & $4(n=11)$ & 21 & 32 \\
\hline $\begin{array}{l}\text { Deans (UG and } P G) \text { and } \\
\text { Foundation Programme } \\
\text { Directors (D_FP) }\end{array}$ & $3(n=11)$ & 19 & 30 \\
\hline $\begin{array}{l}\text { Other Healthcare } \\
\text { Professionals (HCP) }\end{array}$ & $2(n=6)$ & 7 & 13 \\
\hline $\begin{array}{l}\text { Policy and Government } \\
\text { Representatives (P_GVT) }\end{array}$ & $1(n=4)$ & 7 & 11 \\
\hline Employers (EMP) & $1(n=2)$ & 5 & 7 \\
\hline $\begin{array}{l}\text { Patient and Public } \\
\text { Representatives (PPR) }\end{array}$ & $6(n=21) \dagger$ & 4 & 25 \\
\hline Total & $30(n=98)$ & 87 & 185 \\
\hline
\end{tabular}


Table 2 Participant demographics across the four sites, presented by group, collated to protect anonymity

\begin{tabular}{|c|c|c|c|c|}
\hline Stakeholder Group* & $\mathbf{N}$ & Age (years) & Gender & Self-declared ethnicity \\
\hline Trainees (F1 and FRTD) & 67 & $\begin{array}{l}20-24(9 \%) \\
25-29(58 \%) \\
30-34(19 \%) \\
35+(14 \%)\end{array}$ & $\begin{array}{l}\text { Male }(37 \%) \\
\text { Female }(63 \%)\end{array}$ & $\begin{array}{l}\text { British }(77 \%) \\
\text { Other }(23 \%)\end{array}$ \\
\hline $\begin{array}{l}\text { Healthcare stakeholders } \\
\text { (CE, D_FP, HCP, GVT, EMP) }\end{array}$ & 更 & $\begin{array}{l}20-29(2 \%) \\
30-39(13 \%) \\
40-49(22 \%) \\
50-59(44 \%) \\
60+(11 \%) \\
\text { Missing }(8 \%)\end{array}$ & $\begin{array}{l}\text { Male }(59 \%) \\
\text { Female }(41 \%)\end{array}$ & $\begin{array}{l}\text { British }(82 \%) \\
\text { Other }(15 \%) \\
\text { Missing }(1 \%)\end{array}$ \\
\hline PPR & 25 & $\begin{array}{l}30-49(4 \%) \\
50-59(16 \%) \\
60+(72 \%) \\
\text { Missing }(8 \%)\end{array}$ & $\begin{array}{l}\text { Male }(32 \%) \\
\text { Female }(68 \%)\end{array}$ & $\begin{array}{l}\text { British }(96 \%) \\
\text { Other }(0 \%) \\
\text { Missing }(4 \%)\end{array}$ \\
\hline
\end{tabular}

ensure a common aim, understanding and approach. There was one interview schedule but certain questions were omitted or rephrased depending on the applicability for the specific stakeholder group. The interview schedule was created through discussion with multiple stakeholders and by sharing iterative drafts among the research team. Piloting of the interview schedule was undertaken with our patient representative, Dr Philip Bell (see acknowledgements), who suggested substantial changes to the structure of the interview and the phrasing of questions (especially for our patient groups). We also made minor amendments to the question schedule following the early interviews, rewording questions to make them clearer or omitting a question that interviewees could not answer. The finalised interview scheduled is available as Appendix J (p.249) of the final report. ${ }^{7}$

We employed a narrative approach to data collection ${ }^{8}$ but also included a number of direct questions. One of the direct questions, typically posed towards the end of the interview, related to participants' views on aligning full GMC registration with medical school graduation. The wider study ${ }^{7}$ also involved longitudinal audio diaries, which were completed by a subset of the F1 participants $(n=26)$. The data presented in this manuscript are almost entirely drawn from responses to the direct interview question about aligning full registration with graduation but are inevitably informed by the wider interview and audio diary data.

All interviews were transcribed in full. The thematic Framework Analysis method, ${ }^{9}$ involving data familiarisation, thematic framework identification, indexing, charting, mapping and interpretation, enabled contentrelated and process-related themes to be identified. All authors contributed to this process and KK, NK and LVM were directly involved in the coding and code checking. This multianalyst coding was managed through the
Atlas-ti qualitative analysis program to facilitate exploration of patterns in the data, such as differences in stakeholder groups' understandings and experiences.

\section{RESULTS}

Participants had wide-ranging views on aligning full registration with graduation, with members from each stakeholder group presenting arguments in favour and against. Although our study was not designed as an opinion poll, it is noteworthy that more points were raised against the change than in favour (with some participants presenting arguments on both sides): 142 data excerpts were coded overall, with 81 (57\%) comments against the change and $32(22.5 \%)$ for the change. The remainder were neutral. When raising the proposal for registration-graduation alignment, there were many strong initial reactions:

No ((very quick response)). No! ((laughs)) you need that year to get the experience (Female FRTD, ID89).

Following their initial reactions, participants continued to explain in greater depth why they held such views. We identified four key themes in the data incorporating arguments for and against aligning full registration with graduation and we present these with illustrative excerpts from the transcriptions. In doing so, we highlight similarities and differences between stakeholder groups, specifically when arguments are made by individual or subsets of participants in our study.

\section{Theme 1: Safety net}

This theme relates to perceptions of the F1 year as a safety net and was the most common theme, with all participant groups discussing it. No comments on this theme supported the proposed change. Participants 
talked about implications for both patient and learner safety.

Patient safety was by far the most commonly mentioned reason. To ensure patient safety, participants felt that F1 s needed to be closely supervised, adequately supported and provided with incremental responsibility. There was an assumption that full registration would imply higher expectations from the outset of F1 and concerns that graduates would not be sufficiently embedded in the workplace as undergraduates to meet those expectations (from the EMP, HCP, CE and D_FP). Safe prescribing was frequently mentioned in this regard, alongside other errors (eg, Excerpt 1, table 3). FRTDs and CEs noted the importance of 'sign off' by seniors to prevent errors and poor management (eg, Excerpt 2, table 3).

Concerns were voiced (by D_FP and HCP) that earlier full registration might undermine effective supervisory structures. There was a feeling (from GVT, HCP and F1) that being fully registered might add unnecessary further pressure on F1 doctors, leading to stress and anxiety, which might adversely affect patient care. Patient representatives (PPRs) voiced concern about being treated or discharged by newly qualified doctors without adequate supervision (eg, Excerpt 3, table 3). They also questioned the transparency of doctors' stage of training and range of capabilities.

Alongside patient safety, participants recognised the importance of keeping F1s safe. Many described the F1 year as a safe learning space, buffer zone or safety net, enabling F1 doctors to develop as professionals and consolidate undergraduate learning (eg, Excerpt 4, table 3). During this year, it was acknowledged that F1s underwent important transitions, including getting to grips with the pace of clinical practice and developing their own identity as a doctor (eg, Excerpt 5, table 3).

Most F1s in the study valued the protection they felt within the current system. For example, F1s described how not having full registration made it easier to seek advice. This aspect was also appreciated by other participant groups (eg, Excerpt 6, table 3). Senior clinicians, including CEs and D_FPs, emphasised that the F1 year supported the identification and early intervention of struggling trainees, allowing them to grow into competent and safe doctors or possibly helping them to explore other career options (discussed by D_FP). There was a perception that medical schools were not always successful in detecting problems in students' abilities to practise, despite developments in their assessment processes and reporting systems in clinical placements. Some felt that early registration might disrupt existing efforts to smooth the transition from undergraduate education to postgraduate training.

\section{Theme 2: Implications for undergraduate medical education}

Entwined with concerns around patient safety was a call for a 'radical review' of undergraduate curricula if

\section{Table 3 Excerpts from Theme 1, safety net}

\section{Implications for patient safety}

Excerpt 1 "we've seen examples of F1s causing real harm to patients... if they were registered from point of graduation and then given, well I guess, more freedom and more responsibility that wouldn't necessarily be a good thing because, you know, even with the responsibilities and the things they're allowed to do now they're quite capable of causing ... harm to patients" (Female HCP, ID82)

Excerpt 2 "A year is fine but... if I coin of phrase, 'it's where the rubber hits the road', the minute you start to work, and actually I mean yes, we can try and blur those boundaries a little bit by doing a little bit more guided practice or apprenticeship assistantship, but actually that's the point at which you become, you start working, and I think for the protection of the public we probably ought to reserve the right not to approve someone to full practice" (Male CE, ID184)

Excerpt 3 "I do honestly believe that the first year on a ward as an F1 is where they really start to learn something, and learn to deal with things in their own way, with the back-up of somebody there that they can call on if they have to, because their experience doesn't begin to let them cope with that particular situation. I would be very hesitant personally about an F1 doctor- particularly newly qualified- having complete control of what was happening to me" (Male PPR, ID108)

Foundation Year 1 as a safe space for learning

Excerpt 4 "I think foundation year one... has been one of my most my biggest learning experience of my life... I think l've learnt more in this year, in these eight months, that I learnt almost at the whole of medical school. Relevant learning, anyway, for clinical practice, I just think that we're not ready for full registration at the end of medical school" (Female F1, ID122)

Excerpt 5 ' $F 1$, you know, as the juniors would describe it, is just a 'grilly year' where you're firefighting and you're running from crisis to crisis to crisis ... I see the junior year as being important ... same as in nursing, your first year, your first couple of posts, you know, you're finding yourself' (Male HCP, ID80)

Excerpt 6 "Because if you're under supervision, as you are in your foundation year one, it maybe gives you- perhaps gives you more permission to ask questions and put yourself in the role of somebody who doesn't know everything in your learning, whereas as you say if you're fully registered you might feel you have to know all the answers and the risks..." (Female GVT, ID78) 
registration was aligned with graduation (eg, Excerpt 1, table 4). Participants argued that this would need to include developing new outcomes for graduates, so drastically altering the current guidance (at the time of data collection) in the GMC's (2009) Tomorrow's Doctors document, ${ }^{10}$ along with a new national licensing examination (highlighted by CE, D_FP, HCP and EMP: see Excerpt 2, table 4). The only groups that did not comment on this aspect were the PPR, FRTD and F1 groups. Although there were some supporting arguments for this, comments coded to this theme were weighted against change.

Among those who did comment, there was broad agreement that undergraduate curricula would need to provide reassurance that new outcomes developed were appropriate to a registered doctor, and that assessments were in place to demonstrate that they had been achieved. Most undergraduate deans felt that these changes were achievable (Excerpt 3, table 4); others (eg, D_FP, EMPs and HCPs) were less optimistic and felt that clinical service and patients could suffer. There was quite a strong feeling among postgraduate deans that undergraduate medical schools needed to be more resolute about the failing underperformance in students and, rather than seeing it as a weakness, should view it positively (see Excerpt 4, table 4).
The perceived shortfall in experience between new graduates and fully registered doctors was considered to be primarily in the domains of clinical practice and professionalism (eg, practical procedures, decision-making, communication skills, team working). Some stakeholder groups, notably GVT, D_FP and EMP, believed that it was difficult to assess professionalism and doubted whether medical students could become sufficiently embedded in the workplace to gain equivalent experience to a junior doctor in paid employment. There was a widespread belief that the Flyear, in which trainee doctors are part of the workforce, was the best time to develop and assess both clinical and professional competencies. Concerns were raised that a need to focus on clinical skills and professionalism might also have a detrimental impact on coverage of other curricula areas. There was a suggestion, originating with the CE participants, that in order to accommodate the additional requirements, undergraduate curricula might need to be longer (eg, Excerpt 5, table 4).

On a positive note, some participants felt that aligning registration with graduation could introduce greater clarity to the transition from medical student to junior doctor, in terms of organisational responsibility for training and competence expected for each stage. Others felt that it would drive positive change in undergraduate

Table 4 Excerpts from Theme 2, implications for undergraduate medical education

Excerpt 1 "there would need to be a radical review then of the undergraduate curriculum ... I- I've seen areas where F1s have made very, very serious mistakes ... if they were registered they wouldn't have worked again" (Female EMP, ID180)

Excerpt 2 "bringing registration and graduation together has a much, much bigger impact for medical schools, huge impact for medical schools, I think they... will have to significantly change their curricula and put much greater emphasis on that preparation for practice and having somebody who is ready on day one to do something as a foundation year one doctor and I think it will make the ... national licensing exam all the more inevitable ... that is quite a profound change for them and their curriculum and the way that they deliver the end product" (Male D_FP, ID80)

Excerpt 3 "we have a reasonably good final year, there are about three or four what I call 'fallow' weeks, in other words they're weeks where there is nothing in particular in them. Especially in the first semester...they're called 'self-learning' weeks, 'library' weeks or 'do-nothing' weeks...if it comes to pass, I've got plans to re-jig the final year curriculum to use those weeks to give them more experience and more time in the wards, l've drawn up a plan for that and it's going through the various sub committees...there are a few hurdles to go through but if that does come to pass they'll have more time in general practice, more time in medicine and more time in surgery... I'm ahead of time in proposing that" (Male CE, ID06)

Excerpt 4 "you would have to toughen up and be prepared to fail people earlier ... but properly fail" (Male D_FP ID57)"the universities need to take that on. It used to ... we always used to have people that didn't pass, and now that's not acceptable..." (Female D_FP ID60)"because medical schools ... if they have ten percent now who've failed, they would be seen as a failing medical school, and they need to get over that and realise that it isn't a sign of failure, that's a sign of robustness ... it's a sign of robustness in their assessment techniques ..." (Female D_FP ID59)

Excerpt 5 "to me, the key debate is whether you can do that, that within five years of medicine or whether you need a sixth year ... that has been debated and they've come to the conclusion that five years is enough, and it makes me slightly anxious ... that last year, I think, has to be absolutely practical and steeped in the wards... it needs to be patient contact as much as possible" (Male CE, ID96)

Excerpt 6 "Well I think medical education is about trying to improve the quality of care for patients, I think it should be based in practice from the beginning and the more opportunities there are for medical students to practice being a doctor by practicing medicine is more effective they're going to learn and more effective they are going to be as doctors, so the sooner they can take on responsibility, from my perspective, the better. So the simple answer to the question that you've asked is I think it's a good idea as it gives them more responsibility and we can structure the learning better" (Male CE ID02) 
curricula, leading to extended clinical placements and more successful embedding of students within multidisciplinary healthcare teams, which could ultimately benefit patients (eg, Excerpt 6, table 4).

\section{Theme 3: Implications for F1 work practice}

Work practice was mentioned by all groups except PPRs. Most comments suggested that changing the point of registration would have little impact on the daily practice of F1 doctors (F1, FRTD, CE, D_FP, HCP, GOV). F1s generally already felt responsible for their actions and undertook tasks requiring registration, such as discharging patients, albeit under supervision. FRTDs typically reported that their own support-seeking behaviour had not changed after gaining full registration and that asking for support was a gradual change dependent on personal experience.

There was a worry that, once fully registered, junior doctors might forget their personal limitations (eg, Excerpt 1, table 5). However, others felt that the context in which graduates arrived was at least as important as the skills, knowledge and behaviour of the junior doctor: so long as the doctor was supported appropriately, the point at which they are registered was irrelevant (eg, Excerpt 2, table 5). Employers and policymakers talked about their own responsibilities for ensuring trainee and patient safety, including taking a more team-based approach when placing trainees on the rota (eg, Excerpt 3, table 5).

One possible change anticipated was that new graduates might undertake locum work, which could result in lower integration into healthcare teams and a diminished chance of holistic supervision (eg, F1 and other trainee doctors).

\section{Theme 4: Financial, structural and political implications}

Aligning registration with graduation was felt to have financial, structural and political implications (noted by F1, FRTD, CE, D_FP, HCP and GOV groups). FRTD participants were concerned about the financial implications for medical students at the point of graduation, which would be exacerbated by costs associated with registration (eg, Excerpt 1, table 6). If undergraduate education were longer, as discussed in Theme 2, this would have substantial financial implications for medical students and funding bodies/streams.

Structurally, concerns were raised about the potential shift in responsibility to medical schools for preparing individuals for registration, since universities have wideranging missions, which include, but are not limited to, the imperative of patient safety. It was recognised that the aims and agendas of universities and health services are different; and the business of producing graduates and ensuring patient safety may sometimes be in tension. However, it was also recognised that aligning registration with graduation would clarify responsibilities between medical schools and deaneries/Local Education and Training Boards, and fitness to practice proceedings when different locations are involved in training a person across the undergraduate to postgraduate early years (eg, Excerpt 2, table 6). Further, it could simplify the Foundation Programme admission processes and enable coherence of training through greater GMC involvement at all stages, although this benefit was challenged by some (within the GOV group). Structural obstacles also included the timing of $\mathrm{F} 1$ post allocations (by CEs, D_FPs and F1s) and whether graduates would be able to complete their assistantships in the hospitals where they would undertake their F1 posts, which had proved a successful intervention.

Politically, one of the main aspects commented on was that early registration would help with oversubscription for F1 posts, since graduates could work anywhere. Indeed, some stakeholders, notably CEs, D_FPs and HCPs, suggested that the proposed change was mainly politically motivated. Irrespective of the motivation, there was a feeling that greater clarity of what a newly registered and newly graduated trainee would look like in terms of competencies and capabilities would be helpful, which once again brought participants back to considering how undergraduate curricula would need to change as a result (eg, Excerpt 3, table 6).

\section{DISCUSSION}

This qualitative research explored stakeholders' perspectives on the proposed change to align full GMC

Table 5 Excerpts from Theme 3, implications for F1 work practice

Excerpt 1 "we don't want them to think... "that's it now, stabilisers are off, and off you go" ... how is that going to reduce all the risks that we're worried about?" (Female GOV, ID77)

Excerpt 2 "whether you start as an F1 doctor provisionally registered or fully registered it does not change the magnitude of the change we talked about earlier, becoming a doctor. So for me it is that environmental context into which they're introduced, whether you are provisionally registered or fully registered [is] irrelevant so long as it's a safe environment in which you can be supported in an appropriate way that is safe for patients, safe for the learner" (Male D_FP, ID90)

Excerpt 3 "making sure that we have the right level of doctor on at the right time, yeah, so it's something that we will have to work very closely with the university ... it's the responsibilities coming back a year... it seems to be huge, I don't know where to start with it really, but I can see a level of risk and that will only be mitigated by having a different way or rostering a different way of organising rotas ... more team based approach" (Female EMP, ID69) 
Table 6 Excerpts from Theme 4, financial, structural and political implications

Excerpt 1 "it's quite expensive to fully register, and I know that you're going to go and get a job, but it's like sort of four hundred, five hundred pounds and you've got graduation, and you haven't got a job yet, and you're moving house, and you're trying to pay rent, and you've just come out at the end of five years so it's like another expense you really don't need..." (Female FRTD, ID11)

Excerpt 2 "the concept of provisional registration, the students remain officially under the watchful eye of the medical school until you get full registration ... [they are] often working in a place that's far removed from the medical school but when there are difficulties with that trainee they're coming back to the medical school saying "it's your responsibility to- to address these issues" but the student's kind of left" (Male D_FP, ID165)

Excerpt 3 "now there are other political things, which is, we [the Foundation Programme] are oversubscribed. If you are fully registered you can work, if you have provisional registration you can only work in an educationally approved post approved by the GMC ... and that's all you can do, so full registration allows people to go abroad ... so that's the tension in the system ... a driver certainly is the oversubscription ... it's been superseded by other politics and so the GMC are going to have to work through ... what is it and de facto that means that the undergraduate course is going to have to change again" (Male D_FP, ID54)

registration with medical school graduation. We aimed to provide a nuanced understanding of the range of perspectives on this important issue and participants' ideas about the implications. The four main themes identified in the data were: (1) The F1 year as a safety net: patients are protected by close supervision of trainees and 'sign off' by senior doctors to prevent errors; trainees feel protected by their not yet registered status, which allows the F1 year to provide them with a safe place for learning on the job. (2) Implications for undergraduate medical education: participants felt that a 'radical review' of undergraduate curricula, including assessment, would be needed if the change went ahead. (3) Implications for F1 work practice: some felt that there would be no change to $\mathrm{F} 1$ work practice if the change went ahead, while others were concerned that healthcare team integration would be eroded or that F1s might go beyond competency limits. (4) Financial, structural and political implications: cost implications for F1s around earlier GMC registration and potentially longer undergraduate training; clarification or redistribution of responsibilities between undergraduate and postgraduate medical education; and the political context for the proposal and its implications were highlighted. Although more points were raised against the change than in favour, most comments suggested that changing the point of registration would have little impact on the daily practice of F1 doctors. Interestingly, the implications of the proposed change for 4-year graduate entry medicine programmes were not raised by participants at that time, perhaps due to the higher representation of undergraduate entry programme leaders in the participant sample.

As with all studies, there are strengths and limitations to the research design. The number and diversity of our participants is a key strength and our interview approach was well placed to explore the perspectives of a wide range of stakeholders, facilitating a more nuanced account of the potential implications of the proposed change. However, it is worth noting that the discussions around full registration were only one of a number of topics covered in the interviews; thus, the depth of discussion around this issue was reasonably limited. The context of asking the question about full registration towards the end of an interview about preparedness for practice may also have affected the response given by participants because they were sensitised to wider issues about preparedness/unpreparedness for practice. Despite this, when the proposed change was raised, participants tended to have a view and engaged fully in debating its advantages and disadvantages. Resistance to change generally, rather than resistance to the specific change in question, might account for some of the concerns raised, ${ }^{11}$ although the valid reasons given to support their points of view suggest that this was probably a minor component.

The results presented here suggest that support and supervision in the F1 year is perceived as variable but mostly good, contradicting other recent qualitative research suggesting that support and supervision of F1s is variable but frequently poor. ${ }^{12}{ }^{13}$ This apparent contradiction might suggest that the F1 year seems supportive when viewed retrospectively, that more senior medically qualified participants had better supervision when they were at the F1-equivalent stage, or that when faced with the possibility of significant change, the current situation seems good. It is worth noting that in our wider study findings, many foundation doctors cited relationships with their supervisors as one of the most important factors responsible for their feelings of being prepared for practice. $^{7}$ The fairly limited degree to which medical students become fully embedded in healthcare teams as undergraduates has been highlighted previously. ${ }^{14} 15$ New initiatives such as longitudinal integrated clerkships (where medical students spend regular, recurrent placements in the same setting with the same clinical teacher) and student assistantships (where students are fully integrated within a clinical team and responsible for specified duties under supervision) offer possible strategies to counter this. Shadowing (where students become familiar with the specific F1 job that they will take on) is now a mandatory aspect of the medical school to work transition. While 
evidence for the efficacy of assistantships is sparse, the evidence for longitudinal integrated clerkships is growing, ${ }^{16}$ and shadowing has demonstrated positive benefits by providing opportunities for undergraduates to take on responsibility and gain hands-on experience of clinical care. ${ }^{7}$ As such, there may be further opportunities to build on these initiatives.

As well as describing challenges, participants in our study made suggestions about ways to ensure optimal education and training if the timing of registration did change. These include changes to undergraduate education (eg, greater exposure to the practicalities and responsibilities of caring for patients, greater assessment in the domains of clinical practice and professionalism, possibly longer courses), postgraduate supervision and support (eg, ensuring that this is adequate and appropriate despite F1s' registration status, including locum staff) and for organisations (eg, for universities and healthcare providers to work closely to ensure alignment of aims). Many of these recommendations are useful to consider, regardless of whether or not the change is made to the timing of registration.

This study highlights questions that warrant further research: How can we provide medical students with learning experiences that prepare them optimally for their first role as a service provider with responsibility for patient care? How can junior doctors be supervised and supported in ways that enable them to continue learning in busy clinical environments? How can we assure patients and the public that medical practitioners have the appropriate knowledge, skills and behaviours at different stages of medical education and training? Future research should explore strategies to provide more extensive and immersive clinical placements within undergraduate education; developing supervised learning events and workplace-based assessments that reflect the F1 role, particularly in the domain of professionalism; and developing clear statements of expectation for F1 doctors as registered practitioners, rather than provisionally registered practitioners. If full registration is aligned with the point of graduation, it will also be important to evaluate the change process, using a study design that is sophisticated enough to detect possible unintended consequences, such as realist evaluation.

\footnotetext{
Author affiliations

${ }^{1}$ Centre for Research in Professional Learning, Graduate School of Education, University of Exeter, Exeter, UK

${ }^{2}$ Cardiff University School of Medicine, Cochrane Medical Education Centre, Cardiff, UK

${ }^{3}$ Department of Psychology, University of Exeter, Exeter, UK

${ }^{4}$ School of Medicine, Dentistry and Biomedical Sciences, Queen's University Belfast, Belfast, UK

${ }^{5}$ Royal College of Physicians, London, UK

${ }^{6}$ Faculty of Medicine, Nursing \& Health Sciences, Monash University, Melbourne, Victoria, Australia

${ }^{7}$ Cardiff University School of Social Sciences, Cardiff, UK

${ }^{8}$ School of Medicine, Dentistry and Biomedical Sciences, Centre for Medical

Education, Queen's University Belfast, Belfast, UK
}

${ }^{9}$ Chang Gung Medical Education Research Centre, Chang Gung Memorial Hospital, Chang Gung, Taiwan

Acknowledgements The authors wish to acknowledge the participants involved in this research, the wider research team (Christopher Jefferies (CJ), Camille Kostov (CK)), the expert reference group (Adam Dalby, Richard Day, Nassir Domun, Wyn Harris, Dai John, Matt Lambert, Denise McKeegan, Judy McKimm, Peter Riou, Chantelle Rizan, Philip Bell, Steve Riley and Pascal McKeown) and the General Medical Council for funding.

Contributors LVM, CER, AB, GJG and KLM conceived the idea, designed the study, secured the funding and oversaw the ethics approval and data collection at each site. JAC, KK, NK, LVM and GS collected the data in each site (CJ and CK also assisted with the F1 and patient interviews, see acknowledgements). All authors contributed to the data analysis, write-up of the final report, and subsequent drafts of this manuscript. All authors had full access to data collected at their site and access to summaries of the overall data set and can therefore take responsibility for the integrity of the data and the accuracy of the data analysis. LVM, as principal investigator for the study, is the guarantor.

Funding The study was funded by the General Medical Council, which were kept informed of progress with the collection, analysis and interpretation of data, but the researchers remained independent from the funders. The GMC has given its approval for submission of this publication.

Competing interests None declared.

Ethics approval The study was awarded ethics approval in July and August 2013 from each of the four UK sites, one from each country, as detailed in the manuscript. The ethics committees are not named individually in order to protect the anonymity of those sites and study participants.

Provenance and peer review Not commissioned; externally peer reviewed.

Data sharing statement No additional data are available.

Open Access This is an Open Access article distributed in accordance with the Creative Commons Attribution Non Commercial (CC BY-NC 4.0) license, which permits others to distribute, remix, adapt, build upon this work noncommercially, and license their derivative works on different terms, provided the original work is properly cited and the use is non-commercial. See: http:// creativecommons.org/licenses/by-nc/4.0/

\section{REFERENCES}

1. Tooke J. Aspiring to Excellence: Findings and final recommendations of the independent inquiry into modernising medical careers. 2008. http://www.medschools.ac.uk/AboutUs/ Projects/Documents/Final\%20MMC\%20Inquiry\%20Jan2008.pdf

2. Pershing S, Fuchs VR. Restructuring medical education to meet current and future health care needs. Acad Med 2013;88: 1798-801.

3. Greenaway D. Shape of training: securing the future of excellent patient care. London: General Medical Council, 2013. http://www. shapeoftraining.co.uk/static/documents/content/Shape_of_training FINAL_Report.pdf_53977887.pdf

4. General Medical Council. The state of medical education and practice in the UK report: 2014. http://www.gmc-uk.org/publications/ 25452.asp

5. Iversen A, Rushforth B, Forrest K. How to handle stress and look after your mental health. BMJ 2009;338:b1368.

6. Moberly T. Financial incentives should be used to encourage doctors back to UK, BMA says. BMJ Careers. 2015. http://careers. bmj.com/careers/advice/view-article.html?id=20022702

7. Monrouxe L, Bullock A, Cole J, et al. How prepared are UK medical graduates for practice? Final report from a programme of research commissioned by the General Medical Council. General Medical Council, 2014. http://www.gmc-uk.org/How Prepared are UK Medical_Graduates_for_Practice_SUBMITTED_Revised_140614. pdf_58034815.pdf

8. Riessman CK. Narrative methods for the human sciences. Thousand Oaks: Sage Publications, 2008.

9. Ritchie J, Spencer L. Qualitative data analysis for applied policy research. In: Bryman A, Burgess R, eds. Analysing qualitative data. London: Routledge, 1993:173-94. 
10. General Medical Council. Tomorrow's Doctors: outcomes and standards for undergraduate medical education. 2009. http://www. gmc-uk.org/Tomorrow_s_Doctors_1214.pdf_48905759.pdf

11. Pieterse $\mathrm{JH}$, Caniëls MCJ, Homan T. Professional discourses and resistance to change. J Organ Change Manag 2012;25: 798-818.

12. Rees CE, Cleland JA, Dennis A, et al. Supervised learning events in the Foundation Programme: a UK-wide narrative interview study. BMJ Open 2014;4:e005980.

13. Mattick KL, Kelly N, Rees CE. A window into the lives of junior doctors: narrative interviews exploring antimicrobial prescribing experiences. J Antimicrob Chemother 2014;69:2274-83.
14. Illing J, Morrow G, Kergon C, et al. How prepared are medical graduates to begin practice? A comparison of three diverse UK medical schools. Final report to the General Medical Coucil, April 2008. http://www.gmc-uk.org/FINAL_How_prepared_are_ medical_graduates_to_begin_practice_September_08.pdf_ 29697834.pdf

15. Dornan T, Tan N, Boshuizen $\mathrm{H}$, et al. How and what do medical students learn in clerkships? Experience based learning (ExBL). Adv Health Sci Educ Theory Pract 2014;19:721-49.

16. Walters L, Greenhill J, Richards J, et al. Outcomes of longitudina integrated clinical placements for students, clinicians and society. Med Educ 2012;46:1028-41. 